\title{
Roles of Self-Directed Learning and Social Networking Sites in Lifelong Learning
}

\section{Umi Kalsum Mohd Salleh}

Department of Curriculum and Instructional Technology, Faculty of Education, University of Malaya, Kuala Lumpur, Malaysia,umi_salleh@um.edu.my

\section{Hutkemri Zulnaidi}

Department of Mathematics and Science Education, Faculty of Education, University of Malaya, Kuala Lumpur, Malaysia, hutkemri@um.edu.my

\section{Suzieleez Syrene Abdul Rahim}

Department of Mathematics and Science Education, Faculty of Education, University of Malaya, Kuala Lumpur, Malaysia, suzieleez@um.edu.my

\section{Abd Razak Bin Zakaria}

Department of Educational Foundations and Humanities, Faculty of Education, University of Malaya, Kuala Lumpur, Malaysia,abdrazak@um.edu.my

\section{Riyan Hidayat}

Department of Mathematics and Science Education, Faculty of Education, University of Malaya, Kuala Lumpur, Malaysia, riyan160989@gmail.com

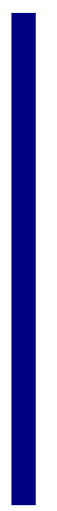

The present research examines the relationship between self-directed learning and SNS that may affect lifelong learning. In study, 170 of the respondents are Masters students and 140 are $\mathrm{PhD}$ students in Malaysia. The study follows a relational survey to investigate and measure the degree of relationship amongst self-directed learning, SNS and lifelong learning. The findings of the research corroborate that self-directed learning positively affects lifelong learning. SEM analysis indicates significant and positive influence of self-directed learning on SNS. SNS are a positive partial mediator between self-directed learning and lifelong learning. In conclusion, self-directed learning positively influences the lifelong learning of students, which is affected by SNS. This study implies that lectures should support preservice teachers to sharpen teachers' self-directed learning and social networking in lifelong learning by giving suitable learning methods and proposing a sufficient teaching and learning atmosphere.

Keywords: confirmatory factor analysis, lifelong learning, self-directed learning, social networking sites, structural equation modelling

Citation: Salleh, U. K. M., Zulnaidi, H., Rahim, S. S. A., Zakaria, A. R., \& Hidayat, R. (2019). Roles of Self-Directed Learning and Social Networking Sites in Lifelong Learning. International Journal of Instruction, 12(4), 167-182. https://doi.org/10.29333/iji.2019.12411a 


\section{INTRODUCTION}

Society based on knowledge and lifelong learning has acquired more serious attention from the state government (Teichler \& Hanft, 2009). Lifelong learning is considered a critical professional development objective for someone in the twenty-first century due to global demographics, environmental imperatives and pervasive access to information (Longworth, 2003). Learners can increase knowledge and competencies by encouraging lifelong learning, in turn successfully overcoming emerging organisational and professional requirements and improving chances. A person who holds a high degree of lifelong learning is increasingly able to obtain constantly changing information and then apply and appraise this information successfully (Oguz \& Ataseven, 2016). The aim of lifelong learning is associated with employment competence and a change of attention from the acquisition of certificates and degrees to the holding of employment (Tremlett, 1997). Lee (2008) affirmed that students who participate in lifelong education usually live a self-controlled life with higher levels of confidence, more open-mindedness, greater awareness of volunteering for others, and more positivity and activity, thereby addressing a sense of isolation in real life. However, the question of how to reduce the level of early school leavers (aged 18 to 24) is the biggest issue in lifelong learning (Luka \& Sungsri, 2015). In terms of teacher education, lifelong learning is also one of the main missions of all educators to invest in their students (Day, 1999). Therefore, teachers can prepare their students for lifelong learning by encouraging several teachinglearning methodologies and increase their application of, and capacity for, lifelong learning. Prospective teachers should be aware of the importance of lifelong learning in their daily lives in terms of promoting students' lifelong learning.

Professional vision is a key element of teacher expertise (Seidel \& Stürmer, 2014) and includes three competences, namely, the competence to describe, explain and predict classroom situations. However, teacher education is inadequate for the lifelong professional needs of teachers (Dolan, 2012). Recent investigations indicated that a minority of students are enrolled for lifelong education (Lee, 2008) and the views of prospective teachers towards lifelong learning competencies are low (Amel, 2014; Çelebi, Özdemir \& Eliçin, 2014). Previous studies have contended that self-directed learning (Atta \& Alghamdi, 2018; Van Rensburg \& Botma, 2015) and social networking (Jaleel \& Om, 2017) are recognised as key features of lifelong learning competencies. Students in higher education do not utilise optimal information technologies (Çelebi, Özdemir \& Eliçin, 2014) in classrooms. Numerous studies found that the majority of learners have low self-directed learning achievements (Atta \& Alghamdi, 2018; Alharbi, 2018). Consequently, if teachers are not developed as self-directed learners (Van Rensburg \& Botma, 2015) and reflective thinkers (Gencel \& Saracaloğlu, 2018), then they cannot prepare their students as independent learners.

However, no standard model to indicate factors that contribute to lifelong learning is available (Arrigo et al., 2013; Dolan, 2012). Previous research has validated that other potential factors influence students, such as self-directed learning (Atta \& Alghamdi, 2018; Loyens, et al., 2008; Manning, 2007; Van Rensburg \& Botma, 2015) and social networking (Jaleel \& Om, 2017; Talug, 2012; Tunney \& Bell, 2011). However, only a 
few studies documented the relationship amongst these variables in lifelong learning. The effects of self-directed learning and social networking on lifelong learning of students have not yet been examined. The present study concentrates on the direct effects of the relationship between self-directed learning and lifelong learning and selfdirected learning and social networking. The indirect effects are the mediating effects of social networking. We extend existing lifelong learning literature by discussing these complex relationships for post graduate students. The research questions guiding the present study are the following:

1. Does self-directed learning directly influence social networking and lifelong learning?

2. Are social networking sites (SNS) a mediator between self-directed learning and lifelong learning?

\section{Lifelong Learning}

Many definitions and interpretations of lifelong learning emerge, in which different views develop diverse operational instruments to measure lifelong learning. Lifelong learning, also known as 'continuing higher education', 'lifelong learning at higher education institutions', 'academic continuing education' or 'learning society' (MorganKlein \& Osborne, 2007), is a strategy that links thinking, learning, planning and practice through self-generated, supported reflective work at several levels (Day, 1999). The term lifelong learning, which usually represents either social order or the individual in a comprehensive sense (Mahoney, 2017), is referred to simply as adult education or the acquisition of skills and training beyond school (Crick, Broadfoot \& Guy Claxton, 2004). Hojat, Nasca, Erdmann, Frisby, Veloski and Gonnella (2003) verified that lifelong learning is a concept including a set of self-initiated activities (behavioural aspects) and information-seeking competencies (capabilities) that are found in people with continual motivation (predisposition) to study and the competency to acknowledge their own learning requirements (cognitive aspect). Crick and Yu (2008) conceptualised a complex definition of lifelong learning that involves a set of dispositions, values and attitudes. This set of dispositions, values and attitudes is frequently formed by people's behaviour and dispositions, which considers social, historical, cultural and personal resources.

\section{Self-Directed Learning}

Self-directed learning, also known as self-planned learning, self-education, selfregulative learning, independent learning and open learning (Dagal \& Bayindir, 2016) is a process where students take individual responsibility by controlling cognitive (selfmonitoring) and contextual (self-management) processes (Garrison, 1997) in diagnosing their learning necessities, formulating learning aims, recognising human and material resources for studying, selecting and executing suitable learning approaches and assessing learning results (Knowles, 1975) through critical reflection (Brookfield, 1995). Patterson, Crooks and Lunyk-Child (2002) concluded that six competencies emerge for self-directed students to reach the self-directed learning process: selfassessment of learning gaps, evaluation of self and others, reflection, information 
management, critical thinking and critical appraisal. Moreover, as self-directed learning refers to individual responsibility or the psychological aspect (Cazan \& Schiopca, 2014), the self-directed student usually holds a high level of self-efficacy, intrinsic motivation, clear goals, proper approaches and willingness to tackle challenges (Garrison, 1997). For the purposes of the current research, self-directed learning will encompass five constructs, namely, awareness, learning strategies, learning activities, evaluation and interpersonal skills.

\section{Social Networking Sites (SNS)}

SNS, the favoured social media platforms utilised by undergraduate students (Smith, Rainie, \& Zickuhr, 2011), refer to 'web-based services that enable people to develop a public or semi-public profile within a bounded system, connect a list of other users with whom they distribute a relationship, and notice and get through their list of relationships and those made by others within the system' (Boyd \& Ellison, 2008). Klamma et al. (2007) reported that digital social networks transform the agency of people by the visibility of 'things', how they are built, managed and framed in discourses. Unal and Akyuz (2015) verified that, in social networking, people usually distribute ideas, interests, comments, messages, videos and images or are looking for people with the same ideas and interests. The advantages of social networking usage are convenient navigation and the ability of learners to ask questions associated with their lessons and for interactive learning processes (Polsgrove \& Frimming, 2013). The examples of social media used amongst young people are Instagram, WhatsApp or Snapchat (Duggan et al., 2015), which aim for educational purposes (Unal \& Akyuz, 2015), social activities and academic information seeking (Aillerie \& McNicol, 2016), and social exchange (Vollum, 2014). Stachowiak (2014) confirmed that social networking is used for the advancement of scientific research institutions, involvement in broader academic discourse and everyday life information seeking.

\section{Relationship Between Self-Directed Learning, SNS and Lifelong Learning}

Manning (2007) claimed that the relationship between self-directed learning and lifelong learning is reciprocal. Self-directed learning is viewed as approaches to pursue learning throughout life, whilst lifelong learning complements students with several skills and competencies needed to pursue their own self-education beyond the end of formal institutional learning. Self-directed learning assists children in understanding information and it serves as a sign for lifelong learning (Jaleel \& Om, 2017). Bidokhta and Assareh (2011) suggested that continuous process of social change learners should be lifelong learning and self-directed learning to able to conquer of challenges and problems. Van Rensburg and Botma (2015) claimed that the success of lifelong learning is the capability to participate in self-directed learning that needs openness to taking chances, a good self-concept, taking the initiative and illustrating independence in learning. Previous research revealed positive relationships between SNS and lifelong learning (Jaleel \& Om, 2017; Talug, 2012; Tunney \& Bell, 2011). This clearly shows that there is a strong relationship between self-directed learning and lifelong learning. Studies were conducted to examine the effect of SNS on self-directed learning. Researchers have corroborated that SNS are closely associated with students' self- 
directed learning (Takabayashi, 2015) with moderate correlation (Takabayashi, 2015). Al-Rahmi and Zeki (2017) reported direct and indirect significant effects of perceived usefulness, perceived enjoyment and perceived ease of use with regard to collaborative learning through the use of social media, which can influence better performance by students.

\section{METHOD}

\section{Research Design}

The present research aims to examine relationships between self-directed learning and SNS that affect lifelong learning using Structural Equation Modelling (SEM) (Byrne, 2012). The current study follows a relational survey model to investigate and measure the degree of relationship amongst self-directed learning, SNS and lifelong learning (Büyüköztürk, Kılıç Çakmak, Akgün, Karadeniz, \& Demirel, 2011). Figure 1 indicates an a priori model integrating variables in the current research developed by theories and prior research. Three main variables emerge, namely, self-directed learning, SNS and lifelong learning, in which the correlation between these variables is indicated by straight arrows. On the basis of relevant literature, the model integrating these variables was not examined previously, and the fit of this model is evaluated via SEM. Students holding self-directed learning will use SNS well, which eventually affects their lifelong learning. Moreover, we also hypothesised that SNS have an indirect effect on lifelong learning.

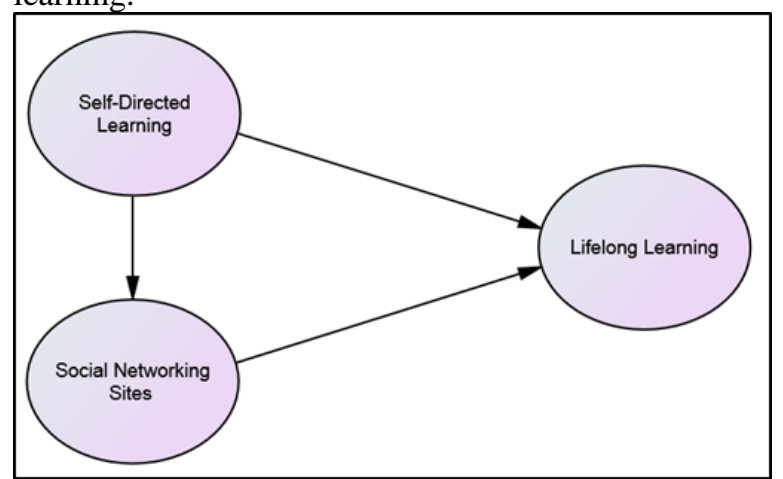

Figure 1

A Priori Model

\section{Participants}

The population of the current research consisted of postgraduate students in Malaysia attending five government universities. Populations were selected because the population was studying at the Faculty of Education in a research-based University. The current research chose groups rather than individuals in the selected Universities. Hence, cluster random sampling was suitable (Fraenkel \& Wallen, 2009). The technique was chosen because all university have some characteristic. The sample of study are Master and Doctor of Philosophy students in Faculty of Education in Research University, 
Malaysia. Higher education systems need to be more flexible and responsive to provide individuals who are able to practice lifelong learning. It also needs to provide a space and a framework of recognition that enables students' mobility through diverse educational paths. It is thus able to increase the participation of the various groups and provide the second chance of pursuing higher education after they have not opportunity. Especially in pursuing Master and Doctor of Philosophy level. Therefore, the current research used 310 postgraduate students in Malaysia. Of the respondents, $104(33.5 \%)$ were male, and $206(66.5 \%)$ were female. One hundred seventy $(54.8 \%)$ of the respondents are Masters students and 140 (45.2\%) are Doctor of Philosophy.

\section{Data Collection Tools}

The self-rating scale of self-directed learning (SRSSDL) (developed by Williamson, 2007), the SNS Intended Use Scale (developed Karal \& Kokoc, 2010) and the Lifelong Learning Scale (developed by Çelebi, Özdemir \& Eliçin, 2014) were used as data collection tools in the present study.

\section{Self-Rating Scale of Self-Directed Learning (SRSSDL)}

The SRSSDL was adopted from Williamson (2007) and involves five sub-constructs classified into awareness, learning strategies, learning activities, evaluation and interpersonal skills. A five-point Likert scale ranging from 1 ('strongly disagree') to 5 ('strongly agree') was employed to measure the SRSSDL. The reliability values of certain scales exceeded the 0.70 desirable standard (awareness, $\alpha=0.70$ ), (learning strategies, $\alpha=0.82$ ), (learning activities, $\alpha=0.81$ ), (evaluation, $\alpha=0.77$ ) and (interpersonal skills, $\alpha=0.77$ ). All composite reliability $(\mathrm{CR})$ values of self-directed learning ranged from 0.60 to 0.82 and exceeded the 0.6 desirable standards (Awang, 2012). This finding affirmed high internal consistency. The average variance extracted (AVE) of the five latent variables ranged from 0.50 to 0.78 and exceeded the 0.5 common cut-off value, demonstrating that the current study presents acceptable discriminant validity (Awang, 2012).

\section{Social Networking Sites Intended Use Scale}

The SNS Intended Use Scale was developed by Çelebi, Özdemir and Eliçin (2014) and involves three sub-constructs classified as the purpose of social interaction and communication, the purpose of knowing and meeting somebody and the purpose of educational purposes. A five-point Likert scale ranging from 1 ('strongly disagree') to 5 ('strongly agree') was employed to measure SNS intended use. The reliability values of certain scales exceeded the 0.70 desirable standard (the purpose of social interaction and communication, $\alpha=0.87$ ), (the purpose of knowing and meeting somebody, $\alpha=0.86$ ) and (the purpose of educational purposes, $\alpha=0.85$ ). All CR values of the SNS Intended Use Scale ranged from 0.85 to 0.88 and exceeded the 0.6 desirable standards (Awang, 2012). This finding affirmed high internal consistency. The AVE of the three latent variables ranged from 0.56 to 0.67 and exceeded the 0.5 common cut-off value, demonstrating that the current study presents acceptable discriminant validity (Awang, 2012). 


\section{Lifelong Learning Scale}

The Lifelong Learning Scale was adopted from Karal and Kokoc (2010) and involves three sub-constructs classified into professional development, personal development and institutional development. A five-point Likert scale ranging from 1 ('strongly disagree') to 5 ('strongly agree') was employed to measure lifelong learning. The reliability values of certain scales exceeded the 0.70 desirable standard (professional development, $\alpha=$ 0.76 ), (personal development, $\alpha=0.70$ ) and (institutional development, $\alpha=0.70$ ). All $\mathrm{CR}$ values of the lifelong learning ranged from 0.65 to 0.77 and exceeded the 0.6 desirable standards (Awang, 2012). This finding affirmed high internal consistency. The AVE of the three latent variables ranged from 0.50 to 0.53 and exceeded the 0.5 common cut-off value, which demonstrated that the current study presents acceptable discriminant validity (Awang, 2012).

\section{Data Analysis}

Data analysis was conducted in three steps. The first step considered considerable data screening-related issues, such as handling missing data, multi-collinearity and identification of outliers and normality using Statistical Package for the Social Sciences 23.0 software. Outliers were identified through a boxplot for each sub-construct. For the examination of normality, the skewness and kurtosis values of each item ranging from -1.96 to +1.96 at the 0.05 significant level (Hair, Black, Babin, \& Anderson, 2010) were used. In terms of multi-collinearity, the correlation amongst factors should less than 0.90 (Kline, 2005). In the second step, confirmatory factor analysis (CFA) and descriptive statistics were carried out. CFA procedures using AMOS 18.0 were used to explore whether the established dimensionality and the factor-loading pattern fit the Malaysian context. Moreover, a measurement model was examined between the related variables for each construct developed from theories and empirical studies. In the final step, an a priori model was evaluated. The model's fit indices of the measurement model and the structural model were also tested, which refer to some criteria.

A bootstrapping procedure with the implementation of bias corrected percentile method (Guan, 2003) was carried out to analyse indirect effects. The maximum likelihood bootstrapping procedure was performed in the current research with a bootstrap sample of 1000 and a bias correction confidence interval of 95\% (Mohamad, Mohamad, Ali \& Awang, 2018). Byrne (2013) and Guan (2003) validated that the bootstrapping procedure in the AMOS program is suitable to manage non-normal data.

Goodness-of-fit was examined through chi-square $(\chi 2)(\mathrm{P}>0.05)$, comparative fit index (CFI > 0.90), Tucker Lewis index (TLI > 0.90) and root mean-square error of approximation (RMSEA < 0.08) (Awang, 2012). In addition, Cronbach's alpha coefficients, CR and AVE were calculated. Cronbach's alpha was computed to determine the reliability of the instrument (total and sub-constructs). CR takes into account that indicators have distinct loadings, whilst AVE captures the variance of its indicator (Awang, Afthanorhan, \& Asri, 2015; Mohamad, Mohammad, Ali, \& Awang, 2018). Hair et al. (2010) reported that alpha values of 0.60 to 0.70 are satisfactory. CR 
should be more than 0.60, and AVE should be higher than 0.50 (Mohamad, Mohammad, Ali, \& Awang, 2018).

\section{FINDINGS}

\section{Preliminary Analysis}

In the current research, the amount of missing data varied from 0 to $0.5 \%$ per item and the missing completely at random (MCAR) (Kline, 2005). Table 1 reveals that a medium level of correlation ( 0.482 to 0.621$)$ exists between the constructs.

Table 1

Correlation Matrix, Means and Standard Deviations

\begin{tabular}{llll}
\multicolumn{1}{c}{ Variable } & 1 & 2 & 3 \\
\hline 1. Lifelong learning & 1 & & \\
2. Self-directed learning & $0.621^{* *}$ & 1 & \\
3. Social networking sites & $0.482^{* *}$ & $0.581^{* *}$ & 1 \\
\hline Skew & -0.330 & -0.114 & -0.703 \\
\hline Kurtosis & 0.038 & -0.566 & 1.057 \\
\hline Mean & 4.20 & 4.30 & 4.11 \\
\hline SD & 0.44 & 0.43 & 0.59 \\
\hline
\end{tabular}

** Correlation is significant at the 0.01 level (2-tailed)

The analysis of the correlations revealed that the correlation between lifelong learning and self-directed learning was significant and moderate $(r=.621, p<0.01)$, lifelong learning and SNS were significant and moderate $(r=.482, p<0.01)$ and self-directed learning and SNS were significant and moderate $(r=.581, p<0.01)$. This correlation indicates that the discriminant validities of the variables were reached because the correlation matrix yielded correlations of less than 0.90 (Kline, 2005). Table 1 lists the means, standard deviations, correlation matrix and skewness and kurtosis for all variables.

In terms of univariate normality, the results of preliminary analysis depict all of the items of the measures of lifelong learning, self-directed learning and SNS reach univariate normality (skewness and kurtosis values are from -0.114 to 1.057). Mardia (1974) reported that, in terms of multivariate normality, the multivariate kurtosis coefficient and critical ratio should be examined. Data were viewed to be not normally distributed when the critical ratio exceeds 5 (Bentler, 1990). In the current research, the multivariate kurtosis coefficient is 580.779 with a critical ratio of 92.371 , indicating that the data set in this study is not normally distributed. Therefore, the bootstrapping procedure was used to obtain more accurate and stable parameter estimates for this data set (Awang, 2012). In addition, the mean values varied amongst variables, with lifelong learning at $\mathrm{M}=4.20$ and $\mathrm{SD}=0.44$, self-directed learning at $\mathrm{M}=4.30$ and $\mathrm{SD}=0.43$ and $\mathrm{SNS}$ at $\mathrm{M}=4.11$ and $\mathrm{SD}=0.59$.

\section{Testing the Measurement Models}

CFA procedures were used to confirm the factorial validity of variables. The item-level factor analysis of self-directed learning provided an acceptable fit in terms of $\chi^{2}=$ 
380.914, $\chi^{2} / d f=3.495, \mathrm{CFI}=0.900, \mathrm{TLI}=0.900$ and RMSEA $=0.090$. All the loadings of self-directed learning items were between 0.61 and 0.80 , which exceeded the common cut-off value of 0.5 (Awang, 2012). In addition, the item-level factor analysis of lifelong learning provided an acceptable fit in terms of $\chi^{2}=64.789, \chi^{2} / d f=2.700$, CFI $=0.946, \mathrm{TLI}=0.920$ and RMSEA $=0.074$. All the loadings of lifelong learning items were between 0.53 and 0.80 , which exceeded the common cut-off value of 0.5 (Awang, 2012). In addition, the item-level factor analysis of social networking provided an acceptable fit in terms of $\chi^{2}=250.270, \chi^{2} / d f=4.907$, CFI $=0.912$, TLI $=0.885$ and RMSEA $=0.099$ and all the loadings of SNS items was between 0.63 and 0.87 . This exceeded the common cut-off value of 0.5 .

\section{Testing the Hypothetical Structural Model}

The outcomes of the SEM analysis in the present study revealed the hypothetical structural model at $\chi^{2}=1549.035, \chi^{2} / \mathrm{df}=2.372, \mathrm{RMSEA}=0.067, \mathrm{TLI}=0.843$, and $\mathrm{CFI}=0.854$. All evaluations resulted in acceptable model fit for the Malaysian context. All factor loadings of the five self-directed learning factors, the three SNS factors and the three lifelong learning factors ranged from 0.548 to 0.797 , from 0.625 to 0.870 and from 0.551 to 0.813 , respectively. The factor loading values exceeded the 0.50 desirable standard (Hair et al., 2010).

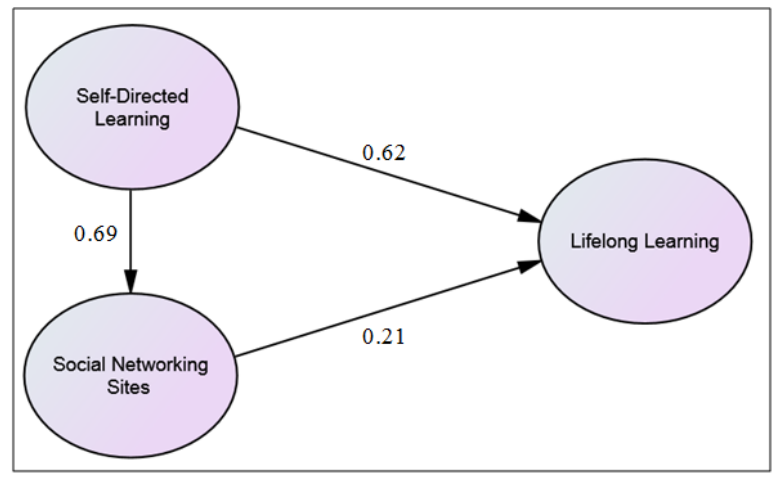

Figure 2

Final Model of the Study

In addition, the model of CFA presented in Figure 2 became the finalized model that indicated relationships amongst self-directed learning, SNS and lifelong learning in the Malaysian context. The final model derived from the current research can be used as an alternative in explaining the prior study on the relationships between self-directed learning, SNS and lifelong learning

\section{Relationships between Self-directed Learning and Lifelong Learning}

We assumed that self-directed learning positively affects lifelong learning. Significant relationships exist between the two constructs $(\beta=0.469, \mathrm{t}=5.504, p<0.01)$. Thus, the hypothesis that students who utilize self-directed learning performed well in lifelong 
learning was fully confirmed. Self-directed learning is one of the factors that contribute to lifelong learning.

\section{Relationships between Self-directed Learning and Social Networking Sites}

We hypothesized that self-directed learning positively affected SNS. Significant relationships exist between the two constructs $(\beta=0.833, \mathrm{t}=9.005, p<0.01)$. Thus, the hypothesis that students who utilize self-directed learning performed well in SNS was fully confirmed. Self-directed learning is one of the factors that contribute to SNS.

\section{Mediating Effects of Social Networking Sites on Relationships between Self- Directed Learning and Lifelong Learning}

We expected that SNS have a mediating effect on the relationship between self-directed learning and lifelong learning. Table 3 illustrates outputs of the mediating effect of SNS on lifelong learning. Mediation effects were determined using bootstrapping procedure to confirm the mediating effect of SNS. A positive partial mediating effect of SNS ( $\beta=$ $0.145, p<0.05)$ for self-directed learning on lifelong learning $(\beta=0.616, p<0.01)$ was found.

Table 3

Output of Mediating Effect

\begin{tabular}{|c|c|c|c|c|c|}
\hline \multirow{2}{*}{ Path } & \multicolumn{2}{|c|}{ Direct effect } & \multicolumn{2}{|c|}{ Indirect effect } & \multirow[t]{2}{*}{ Result } \\
\hline & $\mathrm{B}$ & $\mathrm{P}$ value & $\mathrm{B}$ & Nilai P & \\
\hline SDL $->$ SNS $>>$ LLL & 0.616 & 0.000 & 0.148 & 0.036 & Partial mediation \\
\hline
\end{tabular}

Note: SDL: self-directed learning; SNS: social networking sites; LLL: lifelong learning.

\section{DISCUSSION}

Lifelong learning in preservice teachers as a key element of teacher expertise is accepted. The importance of lifelong learning simplified the investigation of whether self-directed learning and SNS enhance lifelong learning. The purpose of the current research is to examine the relationship between self-directed learning and SNS that might affect lifelong learning in postgraduate students. Research is limited on how SNS is a mediator of the relationship between self-directed learning and lifelong learning, considering the important role of SNS.

SEM analysis indicates the significant and positive effect of self-directed learning on lifelong learning. The expected positive effects of self-directed learning on students' lifelong learning appear to affirm prior research findings (Atta \& Alghamdi, 2018; Loyens, et al., 2008; Manning, 2007; Van Rensburg \& Botma, 2015). One possible reason for this positive relationship is that students who focus on self-directed learning employ a variety of approaches to follow lessons during their life. These learners usually design, supervise and assess their own knowledge. Moreover, to determine success in lifelong learning, students need the ability to engage in self-directed learning which requires openness to learning opportunities, a good self-concept, taking initiative and illustrating independence in knowledge (Van Rensburg \& Botma, 2015). This study 
confirmed that self-directed learning is a factor most important to increase lifelong learning as suggested by Jaleel and Om (2017).

The present study emphasised the significant and direct relationship between SNS and self-directed learning. Our findings corroborated those of previous research (i.e. Takabayashi, 2015), indicating that SNS are positively related to self-directed learning. This construct was also discovered to be important in encouraging the self-directed learning of students. One possible explanation for this finding is that digital social networks provide straightforward navigation and inquiry with regard to questions by students related to their studies and are meaningfully interactive for teaching and learning processes. Gray, Annabell and Kennedy (2010) emphasised that SNS always provide helpful technical assistance and interfaces for students' teamwork, studentgenerated content, student communication and the personalisation and socialisation of student work.

The results of the present study provided further evidence that SNS partially mediates the relationship between self-directed learning and lifelong learning. Thus, SNS may be valuable factors distributing self-directed learning effects on lifelong learning. The present findings corroborate the hypothesis that students with substantial SNS are likely to mediate the relationship between self-directed learning and lifelong learning. The findings support Al-Rahmi \& Zeki (2017) who revealed that SNS is a mediator in students' achievement. Although previous research confirms that self-directed learning is a precondition towards lifelong learning (Loyens, Magda, \& Rikers, 2008), the presence of SNS enhances this relationship. The reason for this connection is that the mediating effects of SNS effectively activate perceived usefulness, perceived enjoyment and perceived ease of use on collaborative learning, which can affect students' learning performance. This result can be clarified by earlier studies, which expressed a positive correlation between SNS and lifelong learning (Jaleel \& Om, 2017; Talug, 2012; Tunney \& Bell, 2011).

One practical implication for lectures is that they should support preservice teachers in order to increase their self-directed learning and social networking in lifelong learning by giving suitable learning methods and proposing a sufficient teaching and learning atmosphere. In addition, on the basis of acquired findings, SNS are positive partial mediators between self-directed learning and lifelong learning. Lectures can help preservice teachers to have robust self-directed learning and require continuing use of SNS beyond the classroom in terms of maximizing perservice teachers' performance in lifelong learning.

The current study has several limitations. Firstly, a full explanation for the relationship between self-directed learning, SNS and lifelong learning in correlational research is difficult although SEM suggests results regarding causal relationships. The structural model in the current research suggests that student's self-directed learning affects students' performance in lifelong learning via students' effect on SNS. Potentially, the relationships amongst these variables are reciprocal; e.g. good performances in lifelong learning enhance students' self-directed learning and social networking. A reciprocal relationship between self-directed learning and lifelong learning was found (Manning, 
2007). Secondly, we employed postgraduate students without identifying them according to their academic level. This meant that the academic level distribution of the sample was skewed and the sample was restricted to university students of the Faculty of Education. Therefore, results of the current research cannot be generalised to other young adults.

Future research also should explore the effect of SNS sub-constructs (e.g. social interaction, educational purposes and meeting or knowing purposes) on learning because of inconsistencies in previous findings. The role of SNS sub-constructs in self-directed learning sub-constructs and lifelong learning can be supplemented to the hypothetical structural equation model. Future studies can consider including the secondary mediators in proposed models of the determinants of self-directed learning, SNS and lifelong learning and thus refining our knowledge in this field. Such an approach would intensify the complexity of the hypothetical structural equation model in order to understand factors contributing towards lifelong learning.

\section{CONCLUSIONS}

The results of this study illustrate that self-directed learning is a factor that has a good impact to lifelong learning. On the other hand, social networking sites are also an intermediary factor for improve lifelong learning. The results of this study can be used as a stepping stone for the government of Malaysia to improve lifelong learning among community and involve social networking to achieve this goal.

\section{ACKNOWLEDGEMENTS}

The authors would like to acknowledge the financial support provided by the University of Malaya under the ESRC (Equity Society Research Cluster) and the Lifelong Learning (ED002B-17SBS) research grant.

\section{COMPETING INTERESTS}

The authors state that they have no personal relationship(s) that might have inappropriately influenced them in writing the current paper.

\section{REFERENCES}

Alharbi, H. A. (2018). Readiness for self-directed learning: How bridging and traditional nursing students differs? Nurse Education Today, 61, 231-234. doi: 10.1016/j.nedt.2017.12.002.

Al-Rahmi, W. M., \& Zeki, A. M. (2017). A model of using social media for collaborative learning to enhance learners' performance on learning. Journal of King Saud University-Computer and Information Sciences, 29, 526-535. doi: 10.1016/j.jksuci.2016.09.002.

Aillerie, K., \& McNicol, S. (2016). Are social networking sites information sources? Informational purposes of high-school students in using SNSs. Journal of Librarianship and Information Science, 1-12. doi: 10.1177/0961000616631612. 
Amel, B. (2014). Teachers' awareness of the significance of lifelong learning: A case study of secondary school teachers of Batna-Algeria. International Scholarly and Scientific Research \& Innovation, 8(11), 3530-3535.

Arrigo, M., Kukulska-Hulme, A., Arnedillo-Sa'nchez, I., \& Kismihok, G. (2013). Metaanalyses from a collaborative project in mobile lifelong learning. British Educational Research Journal, 39(2), 222-247.

Atta, I. S., \& Alghamdi, A. H. (2018). The efficacy of self-directed learning versus problem-based learning for teaching and learning ophthalmology: A comparative study. Advances in Medical Education and Practice, 9, 623-630. doi: 10.2147/AMEP.S171328.

Awang, Z. (2012). A handbook on structural equation modeling (SEM) using Amos. Bangi, Malaysia: MPWS Publication Sdn Bhd.

Awang, Z.; Afthanorhan, A., \& Asri, M. A. M. (2015). Parametric and non-parametric approach in structural equation modeling (SEM): The application of bootstrapping. Modern Applied Science, 9(9), 58-67.

Bentler, P. M. (1990). Comparative fit indexes in structural models. Psychological Bulletin, 107(2), 238-246.

Bidokhta, M. H., \& Assareh, A. (2011). Life-long learners through problem-based and self-directed learning. Procedia Computer Science, 3, 1446-1453. doi: 10.1016/j.procs.2011.01.028.

Boyd, D., \& Ellison, B. N. (2008) Social network sites: Definition, history, and scholarship. Journal of Computer-Mediated Communication, 13(1), 210-230.

Brookfield, S. (1995). Adult learning: An overview. In A. Tuinjman (Ed.), International encyclopedia of education (pp. 1-16). Oxford, England: Pergamon Press.

Büyüköztürk, Ş., Kılıç Çakmak, E., Akgün, Ö., Karadeniz, Ş., \& Demirel, F. (2011). Bilimsel araştırma yöntemleri [Scientific research methods] (10th ed.). Ankara, Turkey: Pegem Akademi Yayıncılık.

Byrne, B. M. (2012). Structural equation modeling with Mplus. Basic concepts, applications, and programming. New York: Routledge.

Byrne, B. M. (2013). Structural equation modeling with AMOS: Basic concepts, applications, and programming. New York: Routledge.

Cazan, A. M., \& Schiopca, B. A. (2014). Self-directed learning, personality traits and academic achievement. Procedia-Social and Behavioral Sciences. 127, 640-644. doi: 10.1016/j.sbspro.2014.03.327.

Çelebi, N., Özdemir, H., \& Eliçin, O. (2014). Studying level of awareness of teachers in terms of their lifelong learning skills. Procedia-Social and Behavioral Sciences, 116, 2030-2038. doi: 10.1016/j.sbspro.2014.01.515.

Clafferty, E. M. (2012). Facilitating social networking within the student experience. International Journal of Electrical Engineering Education, 48(3): 245-251. 
Crick, R. D., Broadfoot, P., \& Claxton, G. (2004) Developing an effective lifelong learning inventory: The ELLI project. Assessment in Education: Principles, Policy \& Practice, 11(3), 247-272, doi: 10.1080/0969594042000304582.

Crick, R. D., \& Yu, G. (2008). Assessing learning dispositions: Is the Effective lifelong learning inventory valid and reliable as a measurement tool? Educational Research, 50(4), 387-402. doi: 10.1080/00131880802499886

Dagal, A. B., \& Bayindir, D. (2016). The investigation of the relationship between the level of metacognitive awareness, self-directed learning readiness and academic achievement of preschool teacher candidates. Universal Journal of Educational Research, 4(11), 2533-2540. doi: 10.13189/ujer.2016.041106.

Day, C. W. (1999). The role of higher education in fostering lifelong learning partnerships with teachers. European Journal of Education, 33(4), 419-432.

Dolan, A. M. (2012). Reforming teacher education in the context of lifelong learning: the case of the BEd degree programme in Ireland, European Journal of Teacher Education, 35(4), 463-479, doi: 10.1080/02619768.2012.696190.

Duggan, M., Ellison, N., Lampe, C., Lenhart, A., \& Madden, M. (2015). Social media update 2014: While Facebook remains the most popular site, other platforms see higher rates of growth. Pew Research Center. Retrieved from http://www.pewinternet. org/files/2015/01/PI_SocialMediaUpdate20141.pdf

Fraenkel, J. R., \& Wallen, N. E. (2009). How to design and evaluate research in education. New York: McGraw-Hill.

Garrison, D. R. (1997). Self-directed learning: Toward a comprehensive model. Adult Education Quarterly, 48(1), 18-33.

Gencel, I., \& Saracaloğlu, A. S. (2018). The effect of layered curriculum on reflective thinking and on self-directed learning readiness of prospective teachers. International Journal of Progressive Education, 14(1), 8-20. doi: 10.29329/ijpe.2018.129.2.

Gray, K., Annabell L., \& Kennedy, G. (2010). Medical students' use of Facebook to support learning: Insights from four case studies. Med Teach, 32, 971-976.

Guan, W. (2003). From the help desk: bootstrapped standard errors In H. J. Newton (Ed.), The Stata journal (pp. 71-80). College Station, TX: Stata Press.

Hair, J. F., Black, W. C., Babin, B. J., \& Anderson, R. E. (2010). Multivariate data analysis (7th Edition). Englewood Cliffs, NJ: Prentice Hall.

Hojat, M., Nasca, T. J., Erdmann, J. B., Frisby, A. J., Veloski, J. J., \& Gonnella, J. S. (2003). An operational measure of physician lifelong learning: Its development, components and preliminary psychometric data. Medical Teacher, 25(4), 433-437. doi: 10.1080/0142159031000137463.

Jaleel, S., \& Om, A. (2017). A study on the relationship between self-directed learning and achievement in information technology of students at secondary level. Universal Journal of Educational Research, 5(10), 1849-1852. doi: 10.13189/ujer.2017.051024.

Karal, H., \& Kokoc, M. (2010). Üniversite öğrencilerinin sosyal ağ siteleri kullanım 
amaçlarını belirlemeye yönelik bir ölçek geliştirme çalışması. Turkish Journal of Computer and Mathematics Education, 1(3), 251-263.

Klamma, R., Chatti, M. A., Duval, E., Hummel, H., Hvannberg, E. H., Kravcik, M., Law, E., Naeve, A., \& Scott, P. (2007). Social software for life-long learning. Educational Technology \& Society, 10(3), 72-83.

Kline, R. B. (2005). Principles and practice of structural equation modeling. New York: The Guilford Press.

Knowles, M. (1975). Self-directed learning: A guide for learners and teachers. New York, NY: Association Press

Lee, H. (2008). University continuing education for lifelong learning in Korea. Journal of Adult and Continuing Education, 14(2), 190-202.

Longworth, N., (2003). Lifelong Learning in action: Transforming education in the 21 st century. London: Routledge.

Long, H. B. (2000). Understanding self-direction in learning. In H. B. Long \& Associates (Ed.), Practice \& theory in self-directed learning (pp.11-24). Schaumburg, IL: Motorola University Press

Loyens, S. M., Magda, J., \& Rikers, R. J. P. (2008). Self-directed learning in problembased learning and its relationships with self-regulated learning. Educational Psychology Review, 20(4), 411-427. doi: 10.1007/s10648-008-9082-7.

Luka, I., \& Sungsri, S. (2015). Lifelong learning strategies and practice in Latvia and Thailand. Policy Futures in Education, 13(4), 529-545. doi: $10.1177 / 1478210315571222$.

Mahoney, M. H. (2017). An academic librarian's search for meaning: A survey of lifelong learning in library literature. The Journal of Academic Librarianship, 43(6), 540.547. doi: 10.1016/j.acalib.2017.05.004.

Manning, G. (2007). Self-directed learning: A key component of adult learning theory. Journal of The Washington Institute of China Studies, 2(2), 104-115.

Mardia, K. V. (1974). Applications of some measures of multivariate skewness and kurtosis in testing normality and robustness studies. Sankhyā: The Indian Journal of Statistics, Series B, 36(2), 115-128.

Mohamad, M., Mohammad, M., Ali, N. A. Mat., \& Awang, Z. (2018). The impact of life satisfaction on substance abuse: Delinquency as a mediator. International Journal of Adolescence and Youth, 23(1), 25-35. doi: 10.1080/02673843.2016.1267021.

Morgan-Klein, B., \& Osborne, M. (2007). The concepts and practices of lifelong learning. New York: Routledge

Oguz, A., \& Ataseven, N. (2016). Relationship between the lifelong learning tendency and information literacy self-efficacy of students. Anthropologist, 24(1), 28-34.

Patterson, C., Crooks, D., \& Lunyk-Child, O. (2002). A new perspective on competencies for self-directed learning. Journal Nurse Education, 41(1), 25-31. 
Polsgrove, M. J., \& Frimming, R. E. (2013). A creative way to utilize social media to enhance fitness and health knowledge. Strategies, 26(2), 3-7.

Seidel, T., \& Stürmer, K. (2014). Modeling and measuring the structure of professional vision in preservice teachers. American Educational Research Journal, 51(4), 739-771. doi: 10.3102/0002831214531321.

Stachowiak, B. (2014) The presence of Polish academics on social networking websites for academics, using the example of employees of Nicolaus Copernicus University. Universal Journal of Educational Research, 2(1), 64-68.

Smith, A., Rainie, L., \& Zickuhr, K. (2011). College students and technology. Pew Research Center. Retrieved from http://pewinternet.org/Reports/2011/ college-studentsand-technology/Report.aspx.

Solmaz, D. Y. (2017). Relationship between lifelong learning levels and information literacy skills in teacher candidates. Universal Journal of Educational Research, 5(6), 939-946. doi: 10.13189/ujer.2017.050605.

Song, L., \& Hill, J. R. (2007). A conceptual model for understanding self-directed learning in online environments. Journal of Interactive Online Learning, 6(1), 27-41.

Takabayashi, T. (2015). Media use as an element of self-directed learning: The learning strategies and media-related behaviors of Japanese university students. International Journal for Educational Media and Technology, 9(1), 80-82.

Talug, D. Y. (2012). Lifelong learning throughout today's occasions namely social media and online games. Procedia-Social and Behavioral Sciences, 46, 4431-4435. doi: 10.1016/j.sbspro.2012.06.269.

Teichler, U. (Ed.). (1996). Special issue on the state of comparative research in higher education. Higher Education, 32(4), 431-465.

Tremlett, L. (1997). An investigation of lifelong learning in the context of traditional educational policy and practice (Unpublished doctoral dissertation). University of Toronto, Toronto.

Tunney, M. M., \& Bell, H. M. (2011). Self-directed learning: Preparing students for lifelong learning. Pharmacy Education, 11(1), 12-15.

Unal, A., \& Akyuz, H. I. (2015). Social networking purposes of pre-service teachers. Procedia-Social and Behavioral Sciences, 186, 825-828. doi: 10.1016/j.sbspro.2015.04.008

Van Rensburg, G. H., \& Botma, Y., (2015). Bridging the gap between self-directed learning of nurse educators and effective student support. Curationis, 38(2), 1-7. doi: 10.4102/curationis.v38i2.1503.

Vollum, M. J. (2014). The potential for social media use in K-12 physical and health education. Computers in Human Behavior, 35, 560-564.

Williamson, S. N. (2007). Development of a self-rating scale of self-directed learning. Nurse Researcher, 14(2), 66-83. doi: 10.7748/nr2007.01.14.2.66.c6022. 